\title{
The Performance Characteristics of Low Voltage Insulators in a Polluted Environment
}

\author{
${ }^{1}$ Boniface Onyemaechi Anyaka, ${ }^{2}$ Muncho Josephine Mbunwe, \\ ${ }^{3}$ Madubuike Kingsley C. \\ ${ }^{1,2,3}$ Department of Electrical Engineering University of Nigeria, Nsukka
}

\begin{abstract}
Low voltage insulators form an essential part of the electric power transmission system. Any failure in the satisfactory performance of low voltage insulators will result in considerable loss of capital, as there are numerous industries that depend upon the availability of an uninterrupted power supply. In this work, an $11 \mathrm{KV}$ porcelain insulator contaminated by different pollutants such as Salt, Cement, Ash, Acid rain and carbon II oxide was tested using a PGK $250 K V$ transformer to ascertain the breakdown voltage of the insulator due to the different pollutants. Test results were recorded as follows: Dry insulator $90 \mathrm{KV}$, dry insulator with water $78.3 \mathrm{KV}$, dry insulator with cement $90 \mathrm{KV}$, wet insulator with cement $20 \mathrm{KV}$, dry insulator with ash $70 \mathrm{KV}$, wet insulator with ash $25 \mathrm{KV}$, dry insulator with Salt $70 \mathrm{KV}$, wet insulator with Salt $20 \mathrm{KV}$ and dry insulator with carbon II oxide $78.3 \mathrm{KV}$.
\end{abstract}

Keywords: pollutant, low voltage, insulator, environment, dielectric.

\section{Introduction}

Insulators are materials in which electricity cannot flow[1]. A true insulator is a material that does not respond to an electric field and completely resists the flow of electric charge. In practice, however, perfect insulators do not exist $[1,2]$. Therefore, dielectric materials with high dielectric constants are considered insulators. In insulating materials valence electrons are tightly bonded to their atoms. These materials are used in electrical equipment as insulators or insulation. Their function is to support or separate electrical conductors without allowing current through [3].

Insulators are meant to work effectively in a clean environment. Our environment is polluted by different types of pollution from industries, cars etc. This paper analyses the effect of an insulator in a polluted environment.

\section{The Mechanism For Insulation Breakdown}

Outdoor insulators are being subjected to various operating conditions and environments. The surface of the insulators is covered by airborne pollutants due to natural or industrial or even mixed pollution [4]. Contamination on the surface of the insulators enhances the chances of flashover[2]. Under dry conditions the contaminated surfaces do not conduct, and thus contamination is of little importance in dry periods [5]. As the surface becomes moist because of rain, fog or dew, the pollution layer becomes conductive because of the presence of ionic solids. The leakage current flows through the conducting surface film,generating heat which tends to increase the film temperature most rapidly at those points where the current density is greatest, i.e. at narrow sections of the insulator, such as the area around the pin. Eventually, the temperature in these areas approaches boiling point, and rapid evaporation of the moisture occurs producing dry areas[6,7]. The development of the dry areas is independentof the insulator type,something that has also been verifiedexperimentally, since the insulator's body diameter differs verylittle from one type to another.Pollution flashover, observed on insulators used in high voltagetransmission is one of the most important problems for powertransmission. Pollution flashover is a very complex problem due to several reasons such as modelling difficulties of the insulatorcomplex shape, different pollution density at different regions,non-homogenous pollution distribution on the surface of insulatorand unknown effect of humidity on the pollution[8]. The performance of insulators under pollutedenvironment is one of the guiding factors in the insulation coordinationof high voltage transmission lines. On the other hand, theflashover of polluted insulators can cause transmission line outage of long duration and over a large area. Flashover of polluted insulatorsis still a serious threat to the safe operation of a power transmissionsystem. It is generally considered that pollution flashoveris becoming ever more important in the design of high voltagetransmission lines.Research on insulator pollution is directed primarily to understandingthe physics of the growth of discharge and to develop amathematical model, which can predict accurately the criticalflashover voltage and critical current $[9,10]$. 


\section{Types Of Contaminant And Sources Of Pollution}

The level and the type of pollution of a region areaassociated with the sources of pollution, as well as the weather factors of the place, are shown in table 1.

TABLE 1: CONTAMINANTS AND THEIR SOURCES OF POLLUTION

\begin{tabular}{|c|c|}
\hline CONTAMINANT & SOURCES OF POLLUTION \\
\hline Salt & $\begin{array}{l}\text { Coastal areas } \\
\text { Salt Industries } \\
\text { High ways with deposits of snow where salt is used to melt the snow }\end{array}$ \\
\hline Cement & $\begin{array}{l}\text { Cement Plant } \\
\text { Construction sites } \\
\text { Rock quarries }\end{array}$ \\
\hline Earth & $\begin{array}{l}\text { Pillowed fields } \\
\text { Earth moving on construction projects }\end{array}$ \\
\hline Fertilizers & $\begin{array}{l}\text { Fertilizer plants } \\
\text { Frequent use of fertilizers in cultivated fields }\end{array}$ \\
\hline Metallic & $\begin{array}{l}\text { Coal mining } \\
\text { Coal handling plants/thermal plants } \\
\text { Coal burning/brick kilns areas }\end{array}$ \\
\hline Volcanic ash & Volcanic activity areas \\
\hline Defecation & Roosts of birds areas \\
\hline Chemical & Wide variety of Chemical/process industries, oil refineries... \\
\hline Smog & $\begin{array}{l}\text { Automobile emissions at highways crossing } \\
\text { Diesel engine emissions at railway crossing /yards }\end{array}$ \\
\hline Smoke & $\begin{array}{l}\text { Wide fire } \\
\text { Industrial burning } \\
\text { Agricultural burning }\end{array}$ \\
\hline
\end{tabular}

$[12,13]$

\section{Laboratory Test Methods For Insulation Breakdown:}

(1) Wet Insulation Test: The insulator was contaminated with Salt and water, ash and water, dust and water,cement and water and then subjected to high voltage of up to $250 \mathrm{KV}$.

(2) Dry Insulation Test:The insulator was contaminated with dry salt, dry ash, dry dust, carbon mono oxide, and cement and then subjected to a high voltage of $50 \mathrm{KV}$.

\section{Experimental Procedure}

A PGK machine was used. The PGK transformer with rating 250KV was connected to the PGK control desk and then the HT indicator was connected to the control desk of the PGK. The secondary side of the transformer was connected to one end of the insulator through a protective resistor whose work is to limit the flow of the current from the transformer to avoid surge while the other end of the insulator wasearthed. The block diagrams test equipment are shown while the test results are shown in Table 2.

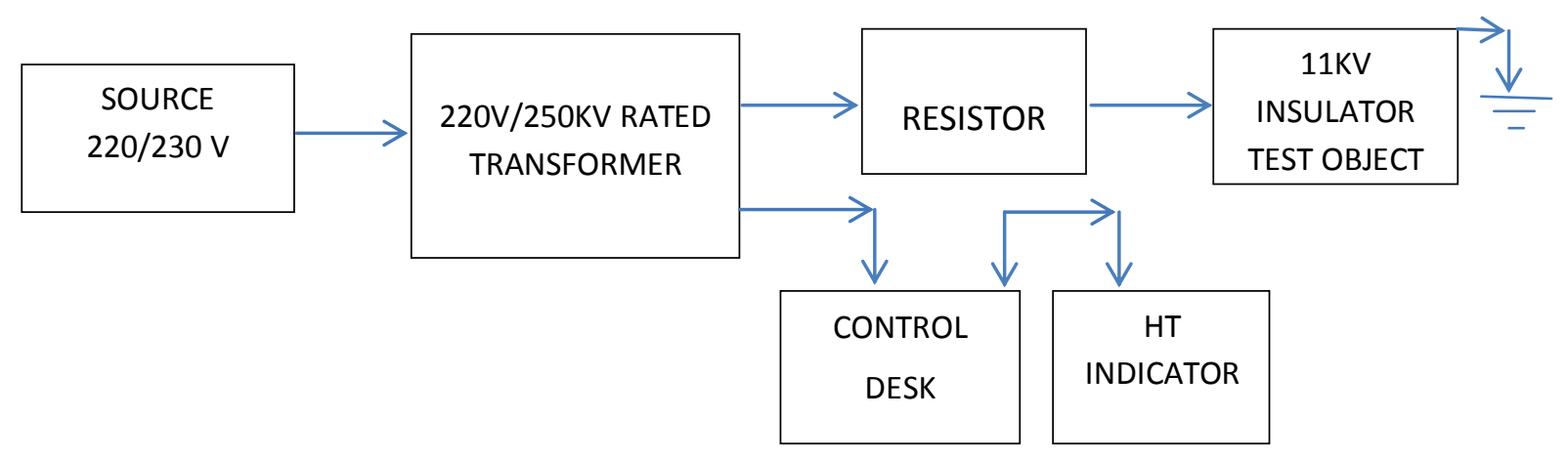

FIG 1: BLOCK DIAGRAM OF AN INSULATION TEST 


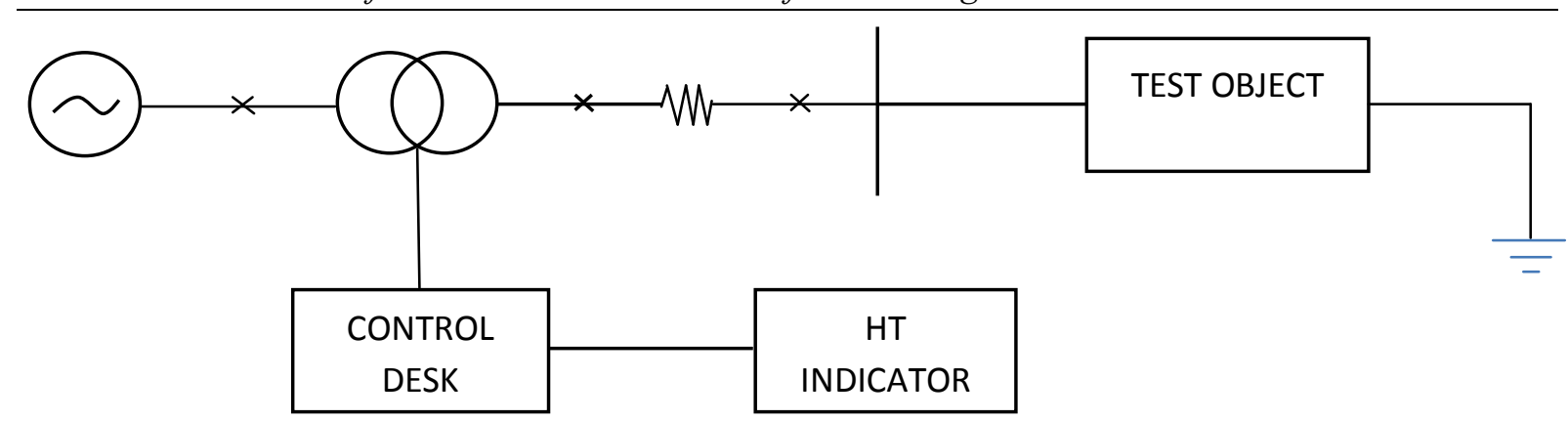

FIG 2: CIRCUIT DIAGRAM OF AN INSULATION TEST

\section{LABORATORY TEST RESULT}

TABLE 2: Breakdown \& Inception Voltage, Leakage Current of Contaminated Insulators.

\begin{tabular}{|c|c|c|c|c|c|c|c|c|c|c|c|c|c|}
\hline $\mathbf{S} / \mathbf{N}$ & Sample & \multicolumn{3}{|c|}{$\mathbf{I}_{\mathbf{C}} \mathbf{V}(\mathbf{K V})$} & \multicolumn{3}{|c|}{$\mathbf{V}_{\mathrm{D}}(\mathbf{K V})$} & \multicolumn{3}{|c|}{$\mathbf{I}_{\mathbf{L}} \mathbf{A}(\mathbf{m A})$} & $A_{V} V_{D}$ & $\mathbf{A}_{V} \mathbf{I}_{C}$ & $\mathbf{A}_{\mathbf{V}} \mathbf{I}_{\mathbf{L}}$ \\
\hline 1 & Dry insulator & 50 & 50 & 50 & 90 & 90 & 90 & 5 & 5 & 4 & 90 & 50 & 4.67 \\
\hline 2 & $\begin{array}{l}\text { Dry insulator } \\
\text { with water }\end{array}$ & 35 & 40 & 42 & 75 & 80 & 80 & 3 & 3 & 2 & 78.3 & 39 & 2.67 \\
\hline 3 & $\begin{array}{l}\text { Dry insulator } \\
\text { with cement }\end{array}$ & 52 & 52 & 52 & 90 & 90 & 90 & 3.5 & 3.5 & 3.5 & 90 & 52 & 3.5 \\
\hline 4 & $\begin{array}{l}\text { Wet insulator } \\
\text { with cement }\end{array}$ & 20 & 20 & 20 & 20 & 20 & 20 & 9 & 9 & 9 & 20 & 20 & 9 \\
\hline 5 & $\begin{array}{l}\text { Dry insulators } \\
\text { with ash }\end{array}$ & 28 & 30 & 30 & 70 & 70 & 70 & 3.2 & 3.0 & 3.1 & 70 & 29.3 & 3.1 \\
\hline 6 & $\begin{array}{l}\text { Wet insulators } \\
\text { with ash }\end{array}$ & 20 & 20 & 20 & 25 & 25 & 25 & 0.9 & 0.9 & 0.9 & 25 & 20 & 0.9 \\
\hline 7 & $\begin{array}{l}\text { Dry insulators } \\
\text { with salt }\end{array}$ & 30 & 30 & 30 & 70 & 70 & 70 & 1.2 & 2 & 2.5 & 70 & 30 & 1.9 \\
\hline 8 & $\begin{array}{l}\text { Wet insulators } \\
\text { with salt }\end{array}$ & 20 & 20 & 20 & 20 & 20 & 20 & 9 & 9 & 9 & 20 & 20 & 9 \\
\hline 9 & $\begin{array}{l}\text { Dry insulators } \\
\text { with CO }\end{array}$ & 50 & 50 & 50 & 80 & 80 & 75 & 3.2 & 3.2 & 3.2 & 78.3 & 50 & 3.2 \\
\hline
\end{tabular}

* The temperature during the experiment is in the range of 28 to $29^{\circ} \mathrm{C}$

Average temperature $\mathrm{T}=\frac{t 1+t 2}{2}=\frac{28+29}{2}=28.5^{\circ} \mathrm{C}$

The pressure during the experiment is $b=1010 \mathrm{mb}$ and it remained constant throughout the experiment.

The Air density factor wasobtained as:

$\mathrm{D}=\frac{b}{1030} \times \frac{273+20}{273+T}$,

Where $; \mathrm{b}=$ atmospheric pressure

$\mathrm{T}=$ Average temperature

$\mathrm{D}=$ Air density factor

$\mathrm{D}=\frac{1010}{1030} \times \frac{273+20}{273+28.5}$

$\mathrm{D}=0.9525$.

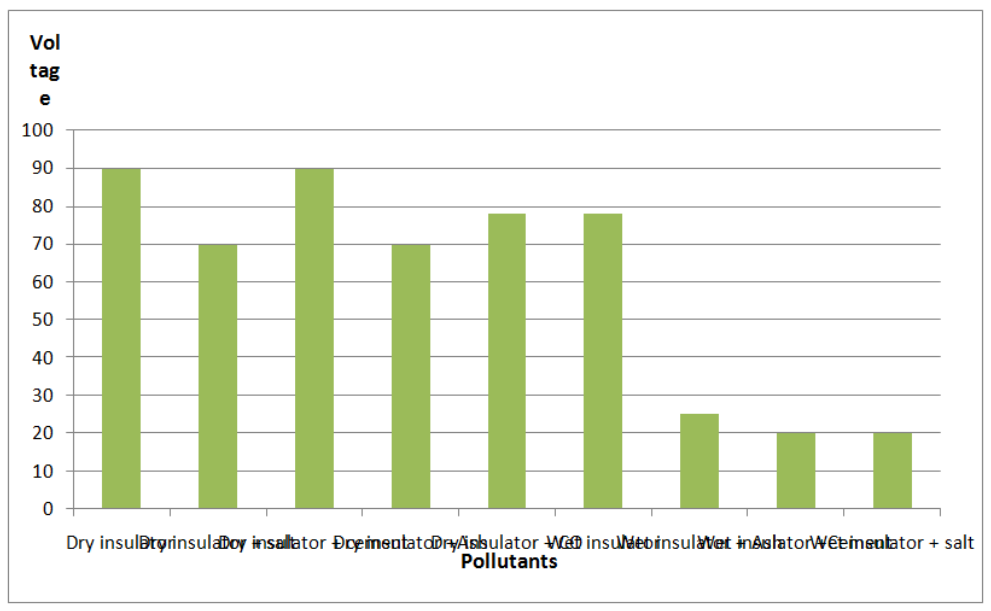

Fig 3: BreakdownVoltage against different level of contaminants 


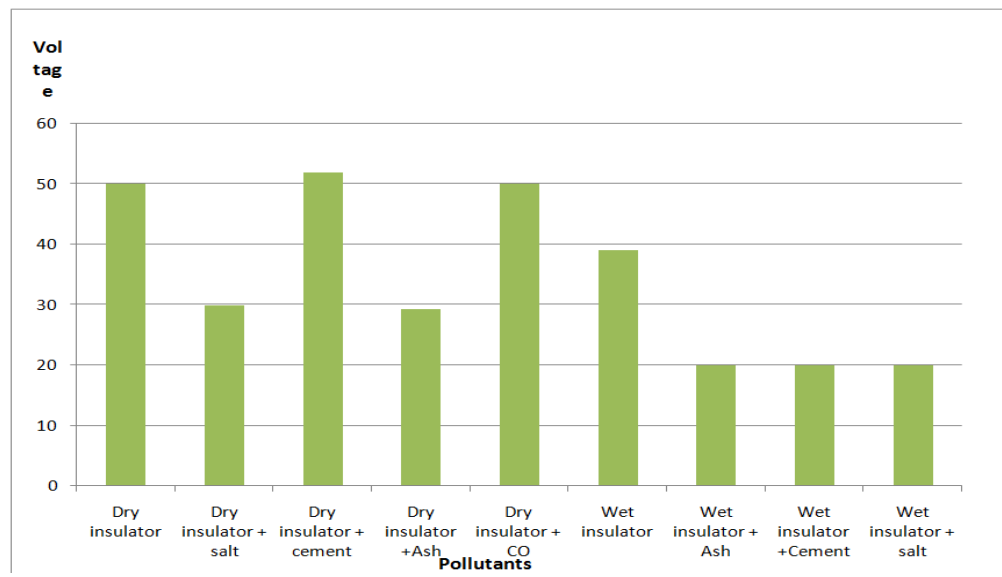

Fig 4: Inception Voltage against different level of contaminants

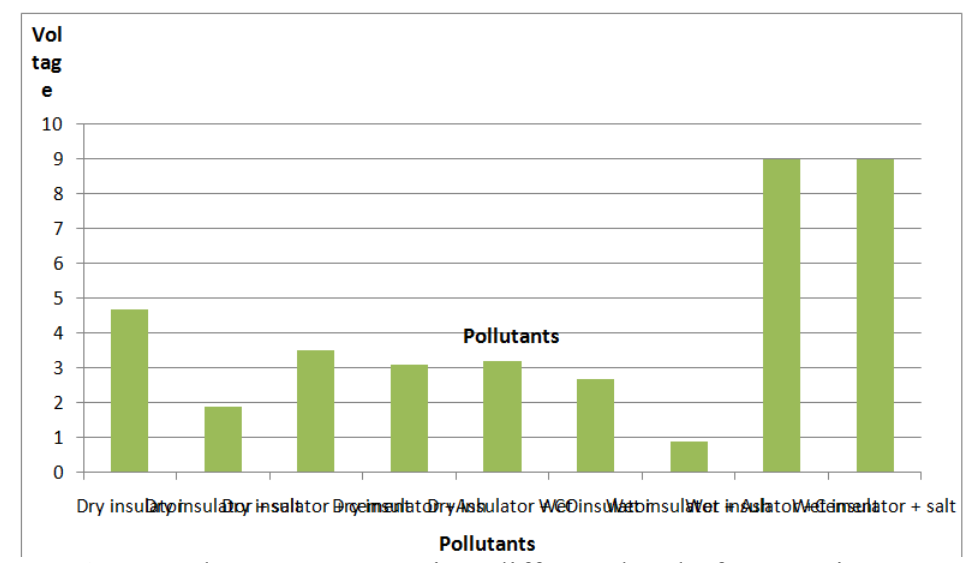

Fig 5:Leakage current against different level of contaminants

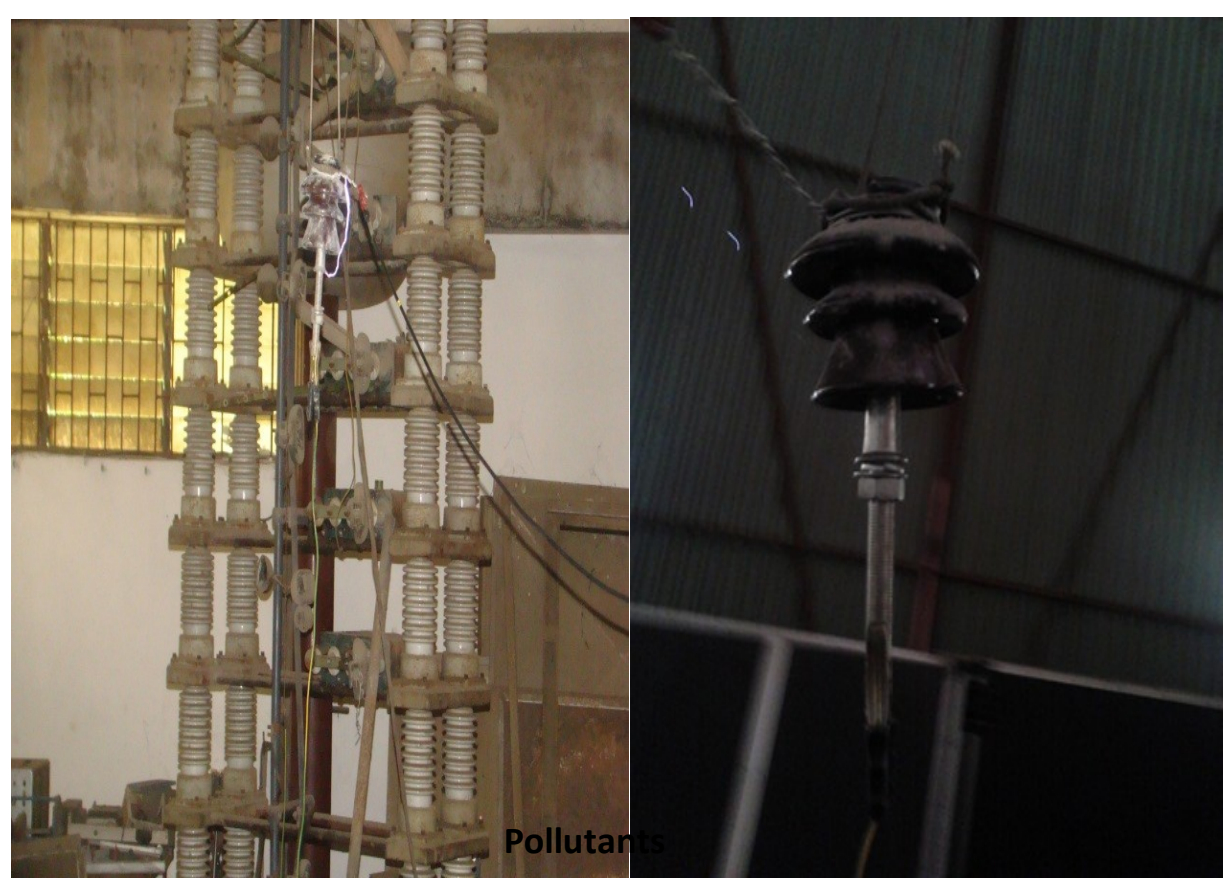

Fig6: Ash flashover Spark and the Insulated Contaminated with Ash. 

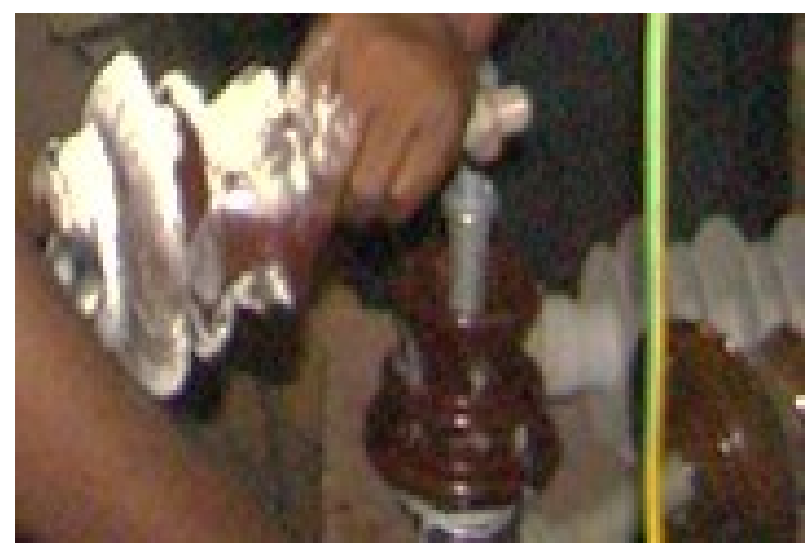

Fig 7: Contamination of Insulator with Cement

The breakdown voltage of $\mathrm{CO}$ produced a spark and the contaminationof the insulator by $\mathrm{CO}$ is shown in fig 8 below,

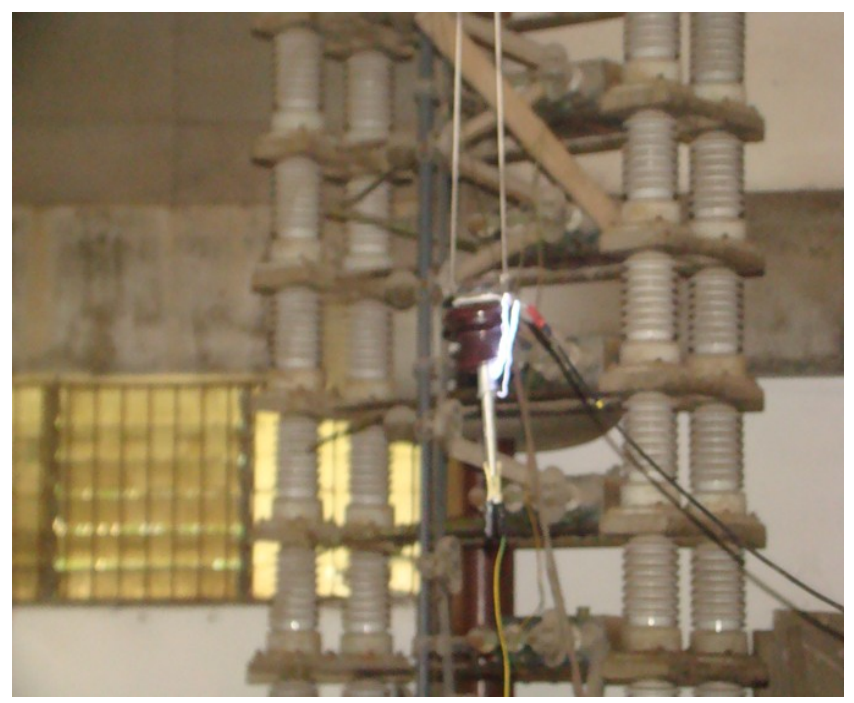

FIG 8: Contamination of Insulator with Co and the Flash over voltage Spark.

\section{Conclusion}

The effect of insulators in an environment polluted with different pollutants such as salt, cement, Ash, Acid water and carbon II oxide was investigated and there breakdown voltages were recorded. Results from test showed that optimal breakdown voltage is realized when the insulator is dry. The result also revealed that the dielectric strength of the insulator decreases depending on the level of contamination/combination of contaminants. Thus the mixture of wet insulator and any contaminant produces very low breakdown voltage and insignificant spark because the dielectric strength of the insulator is reduced.

\section{References}

[1] www.sustainability.vic.gov.au/resources/.../Insulation_benefits.pdf

[2] http://en.wikipedia.org/wiki/Electrical_conductor

[3] http://en.wikipedia.org/wiki/Insulator

[4] http://www.ehow.com/list_7176657_types-insulators-transmission- lines.html

[4] http://www.ehow.com/list_7176657_types-insulators-transmission- lines.html

[5] Gencoglu M.T., Cebeci M., "Investigation of Pollution Flash Over on High Voltage Insulators using Artificial Neural Network", "Expert Systems with Applications" Vol.36, Issue 4. Pp. 7338-7345. (2009).

[6] Ramos Hernanz, José A.1, Campayo Martín, José J and et al "Insulator pollution in transmission lines" available at www.icrepq.com/icrepq06/256-hernanz.pdf.

[7] Cotton J.P, 'Insulator contamination in Power Systems', New York John Wiley and Sons, 1988

[8] Disendorf. W, 'Insulation Co-ordination in High Voltage Electric Power System', London, Butterworth and Co Publisher, 1974

[9] Early B.P 'The Transmission and Distribution of Electric Energy', London the English Press Ltd, 1958

[10] GonenTuran' Electric Power Transmission System Engineering: Analysis and Design', New York, John Wiley \& Sons, 1988

[11] Holtzhousen J.P 'A Critical Evaluation of AC Pollution Flashover Model for HV Insulators', London Butterworth \& Co Publication 1979

[12] Insulator Usage www.insulatorhome.com

[13] Electric Insulator Information www.answer.com 